\title{
Consumption of soda and other sugar-sweetened beverages by 2-year-olds: findings from a population-based survey
}

\author{
Bernice Raveche Garnett ${ }^{1, *}$, Kenneth D Rosenberg ${ }^{2,3}$ and Daniel S Morris 4 \\ 'Department of Society, Human Development and Health, Harvard School of Public Health, 677 Huntington \\ Avenue, Kresge Building, 7th Floor, Boston, MA 021 15, USA: ${ }^{2}$ Office of Family Health, Oregon Public Health \\ Division, Portland, OR, USA: ${ }^{3}$ Department of Public Health and Preventive Medicine, Oregon Health \& Science \\ University, Portland, OR, USA: ${ }^{4}$ Health Promotion and Chronic Disease Prevention, Oregon Public Health \\ Division, Portland, OR, USA
}

Submitted 31 January 2012: Final revision received 19 August 2012: Accepted 21 August 2012: First published online 4 October 2012

\begin{abstract}
Objective: To determine risk factors for consumption of soda and other sugarsweetened beverages (SSB) among 2-year-old children.

Design: The analysis was performed using three linked data sets: the 2004-2005 Oregon Pregnancy Risk Assessment Monitoring Survey (PRAMS); its longitudinal follow-up, 2006-2007 Oregon PRAMS-2; and 2004-2005 Oregon birth certificates. Setting: PRAMS is a surveillance programme supported by the federal Centers for Disease Control and Prevention and implemented by participating state health departments. Using mixed methods, PRAMS surveys women 2-6 months after a live birth. Oregon PRAMS-2 re-interviews respondents shortly after the index child's second birthday. Oregon PRAMS oversamples minority women.

Subjects: Using monthly cohorts, we randomly selected 5851 women from the 2004-2005 birth certificates. In total 1911 women completed both PRAMS and PRAMS-2. The weighted response rate of PRAMS-2 was $43 \cdot 5 \%$.

Results: Almost half of mothers (49.9\%) reported that their child drank SSB on at least $1 \mathrm{~d}$ /week. Mothers whose children drank SSB at least once weekly were more likely to have low income (adjusted $\mathrm{OR}=2 \cdot 83,95 \% \mathrm{CI} 2 \cdot 09,3 \cdot 83$ ) and to eat out on $\geq 2 \mathrm{~d} /$ week $(\mathrm{OR}=2 \cdot 11 \%, 95 \%$ CI $1 \cdot 66,2 \cdot 70)$. Hispanic and nonHispanic black women were most likely to report that their child drank SSB at least once weekly.

Conclusions: Half of mothers reported that their 2-year-old children drank SSB at least once weekly. Public health interventions and policies should address childhood SSB consumption including educating health-care providers and parents.
\end{abstract}

Keywords
Soda
Sugar-sweetened beverages
Child
PRAMS
Oregon

Consumption of sugar-sweetened beverages (SSB) among children of pre-school age has consistently been associated, in both cross-sectional and longitudinal studies, with dental caries ${ }^{(1)}$, increased energy intake ${ }^{(2)}$, displacement of consumption of milk and $\mathrm{Ca}$, and suboptimal diet quality ${ }^{(3)}$. Consumption of SSB has been implicated as a significant cause of obesity ${ }^{(4)}$. The percentage of obese pre-school children in the USA has doubled from $5 \%$ in 1970 to an estimated $9.5 \%$ in $2008^{(5)}$. Overweight children are at least twice as likely to become overweight adults compared with their healthy-weight peers $^{(6)}$.

Recent research has suggested sensitive periods for the development of food and taste preferences among children ${ }^{(7)}$. Although identification of a critical period of weight gain in childhood that would result in subsequent overweight status has not been codified $^{(8)}$, there is evidence suggesting that overweight status persists from infancy through pre-school years ${ }^{(9)}$. Although the effects of early exposure to SSB and preference for sweet or sugary foods have not been unequivocally established, patterning of food and dietary intakes initiates at a young age ${ }^{(10)}$. Therefore, patterns of SSB consumption among young children may be a predictor of future obesity.

In a recent analysis of the National Health and Nutrition Examination Survey (NHANES), Wang et al. documented a significant increase in daily energy intake from SSB in both children and adolescents ${ }^{(11)}$. Based on the aggregated NHANES data, pre-school children consumed an average of $15 \cdot 5 \mathrm{oz}(736 \mathrm{~kJ} / 176 \mathrm{kcal})$ from SSB on a typical day; the majority of these kilojoules being attributed to fruit juices, fruit punches and other fruit drinks. However, carbonated sodas represented almost two-thirds of total SSB energy consumed among adolescents. Black and Mexican-American youth had significantly greater increases in SSB consumption ${ }^{(11)}$, which is consistent with other 
studies documenting the disparate rates of SSB consumption across racial and ethnic categories ${ }^{(12)}$.

Currently there is scant evidence regarding the distribution, prevalence and risk factors associated with soda and other SSB intakes among 2-year-olds. An Italian study described soda consumption among 3-5-year-old children exploring the association with dental caries ${ }^{(13)}$. The only study that has focused on SSB consumption specifically among 2-year-old children highlighted just soda consumption among Mexican Americans in California ${ }^{(14)}$. In that study more than half of the 2-year-olds drank soda and $12 \%$ of them drank soda on one or more days per week. Additionally, 2-year-olds who drank soda had higher birth weight, watched more television and consumed more fast food.

In an attempt to decrease consumption of sugar, a federal tax on all SSB was proposed recently and several state and local districts have moved forward with such proposed taxes ${ }^{(15-17)}$. However questions still persist regarding the consumption patterns, risk factors and prevalence of SSB consumption among young children. To help fill gaps in research and current knowledge regarding risk factors associated with early childhood consumption of SSB, the present study provides evidence from a large population-based sample using three linked data sets to explore risk factors for consumption of soda and other SSB.

\section{Methods}

The present analysis was performed using three linked data sets: the 2004-2005 Oregon Pregnancy Risk Assessment Monitoring Survey (PRAMS) and its longitudinal follow-up, 2006-2007 Oregon PRAMS-2, as well as 2004-2005 birth certificates. PRAMS is a surveillance programme supported by the federal Centers for Disease Control and Prevention (CDC) and implemented by participating state health departments ${ }^{(18)}$. Oregon PRAMS selects mothers using a stratified random sampling scheme. Minority mothers (Hispanic, non-Hispanic black, non-Hispanic American Indian/Alaskan Native and non-Hispanic Asian/Pacific Islander) are oversampled to ensure reliable estimates among these sub-populations ${ }^{(19)}$. Oregon PRAMS-2 re-interviews PRAMS respondents shortly after the index child's second birthday. PRAMS-2 includes questions on health insurance, breast-feeding, maternal smoking and alcohol consumption, maternal depression and social support, as well as questions regarding child nutrition and screen time. PRAMS-2 was administered to all mothers who responded to PRAMS with the exception of mothers who indicated that they did not wish to be contacted again or whose babies were deceased. Like PRAMS, PRAMS-2 is administered by mail with a telephone followup in both English and Spanish. Responses are weighted for oversampling of minorities by the original sampling design, non-response and non-coverage, accounting for the very few birth certificates that were never in the original PRAMS sampling frame. A detailed explanation of the three-stage sampling weight can be found elsewhere ${ }^{(20)}$. PRAMS-2 was re-weighted to account for loss to follow-up of the original PRAMS respondents to ensure that the results are generalizable to the original sampling frame. Using monthly cohorts, we randomly selected 5851 women from 2004-2005 births certificates, 1911 completed both PRAMS and PRAMS-2. The weighted response rate was $43.6 \%$, calculated using a formula as directed by the CDC PRAMS project. Weighted response rates are a widely used methodology in complex survey design and research to reduce sampling bias and to account for varying non-response based on different patterns of selection (e.g. racial/ethnic minority) ${ }^{(21)}$. The women who were lost to follow-up between PRAMS and PRAMS-2 were more likely to be a racial/ethnic minority $(60 \cdot 14 \% v \cdot 40 \cdot 13 \%, P<0 \cdot 001)$, have less than or equal to a high school education $(82 \cdot 78 \% v \cdot 17 \cdot 22 \%, P<0 \cdot 001)$ and were at or below $185 \%$ of the federal poverty level $(53 \cdot 18 \%$ v. $46 \cdot 82 \%, P<0 \cdot 001)$. Mean child age at the time of survey completion was 3.5 months for PRAMS and 25.0 months for PRAMS-2. The Stata statistical software package version 11.0 was used to account for the complex survey design for both the bivariate and multivariate modelling. The SPSS statistical software package version $15 \cdot 0$ was used to produce $\chi^{2}$ statistics and measures of association among selected variables of interest.

\section{Definition of outcome measure}

The main outcome measure in the present analysis was consumption of SSB on at least $1 \mathrm{~d}$ /week when the child was approximately 25 months old. Mothers were asked to 'circle the number of days in a typical week' that their child consumed each of the following: 'milk, fruit juices, fruit drinks/Kool-Aid, soda pop, plain water and sports drinks (e.g. Gatorade, PowerAde)'. Consumption of SSB was defined as consuming either fruit drink/Kool-Aid (FDK) or soda pop on at least $1 \mathrm{~d} /$ week. Mothers who did not answer the soda or the FDK question were excluded from the final analysis ( $n$ 126). Fruit juices were not included in our definition of SSB because the American Academy of Pediatrics does not recommend zero consumption of fruit juice for children of pre-school age $^{(22,23)}$. Sports drinks were not included in this definition of SSB due to discrepancies in underlying characteristics of the population of sports drink consumers that differed from the population of soda and FDK consumers. Consistent with other studies examining the health effects of SSB among pre-school children, SSB was dichotomized to compare children who drank no SSB with children who drank SSB on at least $1 \mathrm{~d} /$ week $^{(24)}$.

\section{Definition of covariates}

Maternal race/ethnicity, maternal age at birth, maternal education, county of maternal residence at the time of birth 
and parity were derived from birth certificates. For the present analysis maternal race/ethnicity was classified as: Hispanic, non-Hispanic white, non-Hispanic black, nonHispanic American Indian/Alaskan Native or non-Hispanic Asian/Pacific Islander. Maternal pre-pregnancy BMI was calculated using self-reported height and weight from the original PRAMS following the CDC calculation for $\mathrm{BMI}^{(25)}$. Maternal pre-pregnancy BMI was classified as 'underweight' $\left(<18 \cdot 5 \mathrm{~kg} / \mathrm{m}^{2}\right)$, 'normal weight' $\left(18.5-24.9 \mathrm{~kg} / \mathrm{m}^{2}\right)$, 'overweight' $\left(25 \cdot 0-29 \cdot 9 \mathrm{~kg} / \mathrm{m}^{2}\right)$ and 'obese' $\left(\geq 30 \cdot 0 \mathrm{~kg} / \mathrm{m}^{2}\right)$. Exclusive breast-feeding at 10 weeks was calculated from PRAMS. Research has documented that mothers introduce complementary food earlier than recommended ${ }^{(26)}$ and this contributes to excessive child weight gain and to the patterning of childhood taste preferences ${ }^{(27,28)}$.

Federal poverty line was calculated using annual household income and the number of household dependants from PRAMS-2 to determine the percentage at or above $185 \%$ of the federal poverty line. Also from PRAMS-2, mothers were asked to 'circle the number of days per week' that their child ate 'restaurant, fast food or take-out food? Take out could be food from a restaurant, supermarket or deli counter'. Eating out was classified as responding as either $0-1 \mathrm{~d} /$ week or $\geq 2 \mathrm{~d} /$ week. This question was not categorized as $0 \mathrm{~d} v$. $\geq 1 \mathrm{~d} /$ week because it included alternative food venues in addition to fast food.

Finally, frequency of family meals together was determined by responses to 'Does your family eat meals together? Check one answer: always, usually, sometimes and never'. This variable was dichotomized to capture families that ate meals together always/usually $v$. sometimes/never.

\section{Statistical techniques}

Descriptive statistics were computed using unweighted data to provide interpretable sample size information among the stratification variables. Weighted data were used in all other analyses. Cross-tabulations and $\chi^{2}$ statistics were generated to check sufficient cell counts within each of the variable categories to be eligible for inclusion in the multivariate model in addition to providing preliminary measures of association among sample characteristics. Simple logistic regression models were constructed to examine the unadjusted odds ratios to determine significant risk factors for consuming SSB on at least $1 \mathrm{~d} /$ week. All correlations were examined at $P<0.05$ to be eligible for inclusion in the multivariate model. Multivariate logistic regression was used to determine adjusted odds ratios and 95\% confidence intervals. SSB consumption was analysed as both a dichotomous ( $0 \mathrm{~d} /$ week $v . \geq 1 \mathrm{~d} /$ week) and continuous variable in the bivariate analyses and similar results were found. In addition to significant variables from the unadjusted odds ratios, other potential cofounders were included in the final multivariate models that have been previously identified in the child SSB literature. To compare regression coefficients across the multivariate logistics regression models, we used post-estimate Wald tests in the Stata suest package.

\section{Ethical approval}

The Oregon PRAMS study protocols and informed consent procedures were approved by the Oregon State Public Health/Multnomah County Public Health Institutional Review Board.

\section{Results}

Table 1 shows the distribution of SSB consumption by $\mathrm{d}$ /week among 2-year-olds in the PRAMS-2 sample. Overall, $49 \cdot 9 \%$ of mothers surveyed reported that their 2-yearold drank SSB at least once weekly. Mothers reported that 2-year-olds were slightly more likely to consume FDK $(37 \cdot 9 \%)$ than soda $(35 \cdot 9 \%)$ on at least $1 \mathrm{~d} /$ week.

Table 2 represents the characteristics of the mothers of 2 -year-old children in the study, divided into four overlapping groups including: (i) all children in the study; (ii) children who drank soda; (iii) children who drank FDK; and (iv) children who drank SSB (i.e. either soda or FDK). Although SSB consumption was the main outcome in the present study and was used in the multivariate model, we explored the consistency of risk factors and covariates across soda, FDK and SSB consumption as this may better inform targeted interventions and policies. Table 2 therefore enumerates each of these outcomes. There was a clear pattern between several demographic variables and the outcome variables (soda, FDK and SSB). The women who were more likely to have children who drank SSB were Hispanic, non-Hispanic black or American Indian/Alaskan Native, low income, less educated, less than 25 years old when the child was born, lived in a rural country type when the child was born and were

Table 1 Distribution of SSB consumption by d/week for 2-year-old children, Oregon PRAMS-2, 2004-2005 births ( $n$ 1785)

\begin{tabular}{|c|c|c|c|c|c|c|}
\hline \multirow[b]{2}{*}{$\mathrm{d} /$ week } & \multicolumn{2}{|c|}{ Soda } & \multicolumn{2}{|c|}{ FDK } & \multicolumn{2}{|c|}{ Soda or FDK (SSB)† } \\
\hline & $n \ddagger$ & $\% \S$ & $n$ & $\%$ & $n$ & $\%$ \\
\hline 0 & 1163 & $64 \cdot 1$ & 1074 & $62 \cdot 1$ & 878 & $50 \cdot 1$ \\
\hline 1 & 296 & $17 \cdot 3$ & 209 & $11 \cdot 8$ & 278 & $15 \cdot 6$ \\
\hline 2 & 160 & $7 \cdot 9$ & 163 & $7 \cdot 6$ & 208 & $9 \cdot 9$ \\
\hline 3 & 73 & 4.9 & 113 & $6 \cdot 4$ & 137 & $8 \cdot 7$ \\
\hline 4 & 45 & $2 \cdot 6$ & 70 & 3.9 & 89 & $5 \cdot 0$ \\
\hline 5 & 18 & $1 \cdot 5$ & 43 & $2 \cdot 7$ & 54 & $3 \cdot 6$ \\
\hline 6 & 6 & 0.3 & 26 & $1 \cdot 1$ & 32 & $1 \cdot 4$ \\
\hline 7 & 24 & $1 \cdot 4$ & 87 & $4 \cdot 4$ & 109 & $5 \cdot 7$ \\
\hline $1-7$ & 622 & 35.9 & 711 & 37.9 & 907 & $49 \cdot 9$ \\
\hline Total & \multicolumn{2}{|c|}{1785} & \multicolumn{2}{|c|}{1785} & \multicolumn{2}{|c|}{1785} \\
\hline
\end{tabular}

SSB, sugar sweetened beverages; PRAMS-2, Pregnancy Risk Assessment Monitoring Survey longitudinal follow-up; FDK, fruit drink/Kool-Aid.

tSSB was created using children whose mothers reported that they drank either soda or FDK.

¥Unweighted number of respondents (excluding those who did not know or did not respond).

$\S$ Weighted percentages to account for survey oversampling, non-response and non-coverage. 
Table 2 Selected sample characteristics of children according to beverage consumption on at least $1 \mathrm{~d} /$ week, Oregon PRAMS-2, 2004-2005 births ( $n$ 1785)

\begin{tabular}{|c|c|c|c|c|c|c|c|c|}
\hline & \multicolumn{2}{|c|}{ Total } & \multicolumn{2}{|c|}{ Soda } & \multicolumn{2}{|c|}{ FDK } & \multicolumn{2}{|c|}{ SSB } \\
\hline & $n+$ & $\% \ddagger$ & $n$ & $\%$ & $n$ & $\%$ & $n$ & $\%$ \\
\hline Total & 1911 & $100 \cdot 0$ & 622 & $35 \cdot 9$ & 711 & $37 \cdot 9$ & 907 & $49 \cdot 9$ \\
\hline \multicolumn{9}{|l|}{ Maternal race/ethnicity } \\
\hline $\mathrm{NH}$ white & 830 & $70 \cdot 4$ & 215 & $30 \cdot 4$ & 231 & $31 \cdot 6$ & 321 & $43 \cdot 4$ \\
\hline Hispanic & 366 & $19 \cdot 8$ & $182^{\star *}$ & $59 \cdot 3$ & $185^{\star \star}$ & $60 \cdot 6$ & $234^{\star \star}$ & $74 \cdot 9$ \\
\hline $\mathrm{NH}$ Al/AN & 226 & $1 \cdot 6$ & $85^{\star \star}$ & 38.5 & $110^{\star \star}$ & $50 \cdot 0$ & $130^{\star \star}$ & $58 \cdot 4$ \\
\hline $\mathrm{NH}$ black & 191 & $2 \cdot 2$ & $72^{*}$ & $42 \cdot 4$ & $98^{\star \star}$ & $58 \cdot 5$ & $113^{\star \star}$ & $66 \cdot 4$ \\
\hline $\mathrm{NH}$ Asian/PI & 292 & $5 \cdot 5$ & 68 & 28.9 & 87 & $36 \cdot 2$ & 109 & $46 \cdot 1$ \\
\hline \multicolumn{9}{|l|}{ Household income } \\
\hline$\leq 185 \% \mathrm{FPL}$ & 946 & $48 \cdot 4$ & $419^{\star *}$ & $49 \cdot 7$ & $490^{\star *}$ & 53.5 & $597^{\star *}$ & $66 \cdot 9$ \\
\hline$>185 \% \mathrm{FPL}$ & 901 & $51 \cdot 6$ & 178 & $21 \cdot 5$ & 187 & $20 \cdot 4$ & 271 & $31 \cdot 2$ \\
\hline \multicolumn{9}{|l|}{ Maternal age at birth } \\
\hline$\leq 25$ years & 637 & $36 \cdot 1$ & $282^{\star *}$ & $48 \cdot 1$ & $333^{\star *}$ & $55 \cdot 0$ & $395^{\star \star}$ & $66 \cdot 3$ \\
\hline$>25$ years & 1274 & $63 \cdot 9$ & 340 & $29 \cdot 1$ & 378 & $28 \cdot 4$ & 513 & $40 \cdot 7$ \\
\hline \multicolumn{9}{|l|}{ Maternal education } \\
\hline$<12$ th grade & 280 & $14 \cdot 3$ & $148^{\star \star}$ & $59 \cdot 0$ & $161^{\star \star}$ & $64 \cdot 9$ & $196^{\star \star}$ & $79 \cdot 5$ \\
\hline$\geq 12$ th grade & 1623 & $85 \cdot 7$ & 471 & $32 \cdot 1$ & 547 & 33.5 & 708 & $45 \cdot 1$ \\
\hline \multicolumn{9}{|l|}{ Pre-pregnancy BMI } \\
\hline Normal/underweight & 1116 & $62 \cdot 5$ & $296^{\star *}$ & $29 \cdot 2$ & $355^{\star *}$ & $32 \cdot 2$ & $449^{* *}$ & $42 \cdot 3$ \\
\hline Overweight/obese & 636 & $37 \cdot 5$ & 250 & $42 \cdot 4$ & 273 & $42 \cdot 3$ & 354 & $56 \cdot 7$ \\
\hline \multicolumn{9}{|l|}{ Child TV \& screen time } \\
\hline$<2 \mathrm{~h} / \mathrm{d}$ & 1471 & $80 \cdot 5$ & $442^{\star *}$ & 33.5 & $526^{\star \star}$ & $36 \cdot 6$ & $666^{\star \star}$ & $47 \cdot 6$ \\
\hline$\geq 2 \mathrm{~h} / \mathrm{d}$ & 401 & $19 \cdot 5$ & 174 & $45 \cdot 9$ & 179 & $43 \cdot 2$ & 235 & $59 \cdot 8$ \\
\hline \multicolumn{9}{|l|}{ Eating out§̧ } \\
\hline$\leq 1 \mathrm{~d} /$ week & 1119 & $60 \cdot 3$ & $311^{* *}$ & $29 \cdot 9$ & $386^{\star *}$ & $36 \cdot 1$ & $488^{* *}$ & $45 \cdot 2$ \\
\hline$\geq 2 \mathrm{~d} /$ week & 758 & $39 \cdot 7$ & 310 & 44.9 & 325 & $40 \cdot 6$ & 418 & $56 \cdot 8$ \\
\hline \multicolumn{9}{|l|}{ County type } \\
\hline Urban & 1497 & $75 \cdot 9$ & $454^{\star \star}$ & $32 \cdot 8$ & $512^{\star \star}$ & $35 \cdot 0$ & $661^{\star \star}$ & $46 \cdot 3$ \\
\hline Rural & 414 & $24 \cdot 1$ & 168 & $45 \cdot 4$ & 199 & $46 \cdot 6$ & 246 & $60 \cdot 9$ \\
\hline \multicolumn{9}{|l|}{ EBF for 10 weeks } \\
\hline Yes & 736 & $53 \cdot 3$ & $213^{\star *}$ & $30 \cdot 7$ & $219^{\star \star}$ & $27 \cdot 0$ & $293^{\star \star}$ & $39 \cdot 7$ \\
\hline No & 802 & $46 \cdot 7$ & 282 & $39 \cdot 0$ & 300 & $44 \cdot 4$ & 382 & $55 \cdot 9$ \\
\hline
\end{tabular}

PRAMS-2, Pregnancy Risk Assessment Monitoring Survey longitudinal follow-up; FDK, fruit drink/Kool-Aid; SSB, sugar sweetened beverage; $\mathrm{NH}$, non-Hispanic; Al, American Indian; AN, Alaskan Native; PI, Pacific Islander; FPL, federal poverty level; TV, television; EBF, exclusive breast-feeding.

Significant $P$ value generated from $\chi^{2}$ statistic: ${ }^{*} P<0.05,{ }^{* *} P<0.01$.

+Unweighted number of respondents (excluding those who did not know or did not respond).

$\ddagger$ Weighted percentages to account for survey oversampling, non-response and non-coverage.

$\S$ Eating out refers to restaurant take out, deli, supermarket and fast food.

overweight/obese before their child was born. Children who watched television for $\geq 2 \mathrm{~h} / \mathrm{d}$ and who ate out more frequently were more likely to consume any category of SSB at least once weekly. For soda, FDK and SSB consumption, children of Hispanic mothers had disproportionately higher rates of SSB consumption than children of non-Hispanic white mothers. Using multivariate logistic regression, we examined the risk factors for consumption of soda, FDK and SSB (either soda or FDK) on at least $1 \mathrm{~d}$ /week, separately.

Table 3 displays the adjusted odds ratios and the 95\% confidence intervals from the multivariate analyses of risk factors for soda, FDK and SSB. After controlling for household income, maternal age at birth, maternal education, maternal pre-pregnancy BMI, child screen time, frequency of meals consumed outside the home, county type and breast-feeding, there were significant racial/ethnic disparities in consumption of SSB where Hispanic mothers and non-Hispanic black mothers were significantly more likely to report that their child drank
SSB on at least $1 \mathrm{~d}$ /week compared with non-Hispanic white mothers (OR $=1 \cdot 85,95 \%$ CI 1·19, $2 \cdot 87$ and OR $=1 \cdot 64$, $95 \%$ CI 1.02, 2.64, respectively). Lower household income was the strongest predictor of SSB consumption ( $\mathrm{OR}=2 \cdot 83,95 \% \mathrm{CI} 2 \cdot 09,3 \cdot 83)$ in the multivariate model. Similar to SSB, maternal Hispanic ethnicity was a significant predictor for soda consumption (OR $=1 \cdot 85,95 \%$ CI $1 \cdot 20,2 \cdot 87$ ), while all other racial and ethnic groups sampled were not significant after adjustment for other covariates. Unlike soda and SSB consumption, there were significant racial/ethnic differences across all groups represented compared with their non-Hispanic white counterparts in regard to FDK consumption on at least $1 \mathrm{~d}$ /week after controlling for all relevant covariates and confounders.

In order to compare the magnitude of the regression coefficients of interest across the three outcomes, postestimation Wald tests were computed to assess whether there was a global difference across the three separate outcomes. Overall, there were no significant differences 
Table 3 Comparison of risk factors for consumption of soda, FDK and SSB on at least $1 \mathrm{~d} /$ week, Oregon PRAMS-2, 2004-2005 births ( $n$ 1785)

\begin{tabular}{|c|c|c|c|c|c|c|}
\hline & \multicolumn{2}{|c|}{ Soda } & \multicolumn{2}{|c|}{ FDK } & \multicolumn{2}{|c|}{ SSBt } \\
\hline & Adjusted OR & $95 \% \mathrm{Cl}$ & Adjusted OR & $95 \% \mathrm{Cl}$ & Adjusted OR & $95 \% \mathrm{Cl}$ \\
\hline \multicolumn{7}{|l|}{ Maternal race/ethnicity } \\
\hline $\mathrm{NH}$ white & Ref. & & Ref. & & Ref. & \\
\hline Hispanic & $1 \cdot 85$ & $1 \cdot 20,2 \cdot 87$ & $1 \cdot 79$ & $1 \cdot 14,2 \cdot 81$ & $1 \cdot 85$ & $1 \cdot 19,2 \cdot 87$ \\
\hline $\mathrm{NH} \mathrm{Al} / \mathrm{AN}$ & $1 \cdot 01$ & $0.65,1.56$ & $1 \cdot 61$ & $1 \cdot 08,2 \cdot 42$ & $1 \cdot 22$ & $0.81,1 \cdot 84$ \\
\hline $\mathrm{NH}$ black & $1 \cdot 16$ & $0 \cdot 73,1 \cdot 84$ & $2 \cdot 07$ & $1 \cdot 27,3 \cdot 37$ & $1 \cdot 64$ & $1 \cdot 02,2 \cdot 64$ \\
\hline NH Asian/PI & $1 \cdot 00$ & $0.66,1.51$ & 1.56 & $1 \cdot 05,2 \cdot 32$ & $1 \cdot 20$ & $0 \cdot 82,1 \cdot 75$ \\
\hline \multicolumn{7}{|l|}{ Household income } \\
\hline $\begin{array}{l}\leq 185 \% \mathrm{FPL} \\
>185 \% \mathrm{FPL}\end{array}$ & $\begin{array}{l}2 \cdot 11 \\
\text { Ref. }\end{array}$ & $1 \cdot 53,2 \cdot 91$ & $\begin{array}{l}2 \cdot 93 \\
\text { Ref. }\end{array}$ & $2 \cdot 15,3 \cdot 99$ & $\begin{array}{l}2 \cdot 83 \\
\text { Ref. }\end{array}$ & $2 \cdot 09,3 \cdot 83$ \\
\hline \multicolumn{7}{|l|}{ Eating outł } \\
\hline $\begin{array}{l}\geq 2 \mathrm{~d} / \text { week } \\
\leq 1 \mathrm{~d} / \text { week }\end{array}$ & $\begin{array}{l}2 \cdot 36 \\
\text { Ref. }\end{array}$ & $1 \cdot 79,3 \cdot 13$ & $\begin{array}{l}1 \cdot 81 \\
\text { Ref. }\end{array}$ & $1 \cdot 37,2 \cdot 41$ & $\begin{array}{l}2 \cdot 11 \\
\text { Ref. }\end{array}$ & $1 \cdot 66,2 \cdot 70$ \\
\hline \multicolumn{7}{|l|}{ Maternal age at birth } \\
\hline $\begin{array}{l}\leq 25 \text { years } \\
>25 \text { years }\end{array}$ & $\begin{array}{l}1 \cdot 60 \\
\text { Ref. }\end{array}$ & $1 \cdot 17,2 \cdot 19$ & $\begin{array}{l}1 \cdot 66 \\
\text { Ref. }\end{array}$ & $1 \cdot 22,2 \cdot 27$ & $\begin{array}{l}1 \cdot 43 \\
\text { Ref. }\end{array}$ & $1 \cdot 09,1 \cdot 88$ \\
\hline \multicolumn{7}{|l|}{ Maternal education } \\
\hline $\begin{array}{l}<12 \text { th grade } \\
\geq 12 \text { th grade }\end{array}$ & $\begin{array}{l}1 \cdot 67 \\
\text { Ref. }\end{array}$ & $1 \cdot 03,2 \cdot 79$ & $\begin{array}{l}1.52 \\
\text { Ref. }\end{array}$ & $0 \cdot 92,2 \cdot 48$ & $\begin{array}{l}1 \cdot 74 \\
\text { Ref. }\end{array}$ & $1 \cdot 03,2 \cdot 96$ \\
\hline \multicolumn{7}{|l|}{ County type } \\
\hline $\begin{array}{l}\text { Rural } \\
\text { Urban }\end{array}$ & $\begin{array}{l}1 \cdot 30 \\
\text { Ref. }\end{array}$ & $0 \cdot 92,1 \cdot 82$ & $\begin{array}{l}1 \cdot 58 \\
\text { Ref. }\end{array}$ & $1 \cdot 11,2 \cdot 20$ & $\begin{array}{l}1 \cdot 61 \\
\text { Ref. }\end{array}$ & $1 \cdot 15,2 \cdot 26$ \\
\hline \multicolumn{7}{|l|}{ Child TV \& screen time } \\
\hline $\begin{array}{l}\geq 2 \mathrm{~h} / \mathrm{d} \\
<2 \mathrm{~h} / \mathrm{d}\end{array}$ & $\begin{array}{l}1 \cdot 73 \\
\text { Ref. }\end{array}$ & $1 \cdot 07,2 \cdot 81$ & $\begin{array}{l}1 \cdot 07 \\
\text { Ref. }\end{array}$ & $0.77,1.49$ & $\begin{array}{l}1 \cdot 38 \\
\text { Ref. }\end{array}$ & $0.99,1.91$ \\
\hline \multicolumn{7}{|c|}{ Maternal pre-pregnancy BMI } \\
\hline $\begin{array}{l}\text { Overweight/obese } \\
\text { Normal/underweight }\end{array}$ & $\begin{array}{l}1 \cdot 49 \\
\text { Ref. }\end{array}$ & $1 \cdot 11,1 \cdot 99$ & $\begin{array}{l}1 \cdot 20 \\
\text { Ref. }\end{array}$ & $0 \cdot 90,1 \cdot 61$ & $\begin{array}{l}1 \cdot 50 \\
\text { Ref. }\end{array}$ & $1 \cdot 13,1.99$ \\
\hline \multicolumn{7}{|l|}{ EBF for 10 weeks } \\
\hline $\begin{array}{l}\text { No } \\
\text { Yes }\end{array}$ & $\begin{array}{l}1 \cdot 27 \\
\text { Ref. }\end{array}$ & $0 \cdot 97,1 \cdot 68$ & $\begin{array}{l}1 \cdot 45 \\
\text { Ref. }\end{array}$ & $1 \cdot 10,1 \cdot 91$ & $\begin{array}{l}1 \cdot 37 \\
\text { Ref. }\end{array}$ & $1 \cdot 05,1 \cdot 78$ \\
\hline
\end{tabular}

FDK, fruit drink/Kool-Aid; SSB, sugar sweetened beverage; PRAMS-2, Pregnancy Risk Assessment Monitoring Survey longitudinal follow-up; NH, non-Hispanic; Al, American Indian; AN, Alaskan Native; PI, Pacific Islander; FPL, federal poverty level; TV, television; EBF, exclusive breast-feeding; Ref, referent category. tSSB refers to drinking either soda or FDK on at least $1 \mathrm{~d} /$ week.

‡Eating out refers to restaurant take out, deli, supermarket and fast food.

across the regression coefficients between soda and SSB consumption $(P=0 \cdot 07)$. The global test comparing SSB and FDK was significant $(P=0 \cdot 01)$ and after computing individual Wald tests on the regression coefficients, the association between eating out and beverage consumption was statistically significantly greater for the SSB model compared with the FDK model $(\mathrm{OR}=2 \cdot 11 v$. $\mathrm{OR}=1 \cdot 81, P=0 \cdot 04)$. The global test comparing FDK and soda was also significant $(P=0 \cdot 007)$ and after computing individual Wald tests on the regression coefficients, the association between maternal race/ethnicity (specifically non-Hispanic black, American Indian/Alaskan Native and Asian/Pacific Islander in comparison to non-Hispanic white mothers) and beverage consumption was statistically significantly greater for the FDK model compared with the soda model $(P=0 \cdot 036,0 \cdot 046,0 \cdot 046$, respectively).

\section{Discussion}

We found that almost half of mothers reported that their 2-year-old child drank soda or other SSB in the past week. The consumption of SSB by young children probably contributes to children's patterning of taste preferential for sweet and sugary foods, less adequate diet quality and is most likely a robust contributor to the epidemic of childhood obesity ${ }^{(29-31)}$. Children and adults who consume soda also have a greater amount of added sugars in their diet than adults and children with a healthier beverage consumption profile $\mathrm{e}^{(32,33)}$. Compared with nonconsumers of soda, 5-year-old girls who consumed soda at baseline had lower milk intake across a 10-year study period which was associated with a diet lower in vitamin $\mathrm{D}$ and $\mathrm{Ca}$ at follow-up ${ }^{(34)}$. Young children's drinking of soda and other SSB: (i) tracks over time with increased exposure $^{(35)}$; (ii) leads to weight gain ${ }^{(31)}$ and is associated with poor diet quality; and (iii) has deleterious ramifications on oral health ${ }^{(33)}$.

Lower household income was the single strongest predictor of infant consumption of SSB. This finding is consistent with other evidence documenting the inverse association between SSB consumption and income ${ }^{(36,37)}$. Burgeoning evidence highlights the low cost of energydense foods, unequal and affordable access to healthy foods and the high palatability of sugary and fatty foods as formidable causal factors producing this income-diet gradient ${ }^{(38-40)}$. The early introduction of soda and other sugary foods may be a coping mechanism of food insecurity 
and utilized as a vehicle to quell satiety and behavioural agitation among toddlers ${ }^{(41)}$, but little empirical evidence has been generated that supports this assertion.

We found that Hispanic mothers were the most likely to report that their toddlers drank SSB. Of the Hispanic mothers in Oregon, $77.5 \%$ are foreign-born (most born in Mexico). These data highlight the need for culturally tailored and targeted interventions among the Hispanic population in Oregon regarding soda and other SSB consumption among toddlers. Soda and other high-fat foods may symbolize economic success and improved circumstances $^{(42)}$ for recent Mexican immigrants with little recognition of adverse health effects associated with overweight infants ${ }^{(41)}$. Further qualitative research should be undertaken to explore acculturation, influences of extended family members on infant diet and cultural perception of healthy infant weight, which have previously been identified as major factors contributing to disparate rates of overweight among Mexican-American children ${ }^{(43,44)}$.

To the authors' knowledge, the present study is the first one to partition the risk factors unique to soda, FDK and SSB among a population-based sample of 2-year-olds. Almost half of mothers reported that their child drank SSB on at least $1 \mathrm{~d} /$ week. Interesting patterns of association across the three outcomes emerged utilizing post-estimation techniques. While the regression coefficients of soda and SSB consumption are comparable, the association between maternal race/ethnicity and beverage consumption was significantly greater for FDK than for soda consumption, where non-Hispanic black, American Indian and Asian/ Pacific Islander mothers were more likely to report that their child consumed FDK at least once weekly compared with non-Hispanic white mothers. Even at age 2 years, there are stark racial and ethnic disparities in SSB consumption that persist even after controlling for demographic characteristics and other associated covariates. This evidence supports tailored and targeted programmes, policies and initiatives by both maternal race/ethnicity and beverage type, as it appears that fruit drinks are more universally consumed compared with soda among toddlers in Oregon.

Parents, physicians and teachers should be educated about the dangers of SSB and mobilized to change patterns of SSB use by children. The American Dietetic Association has stated that sweetened beverages and added sugar should be avoided or used sparingly in the case of consumption among children ${ }^{(45)}$ but no formal recommendation from the American Academy of Pediatrics has yet been released regarding young children drinking SSB. Healthcare providers should be reminded of the importance of counselling parents to not give SSB to young children. Additional taxes on soda and other SSB might have the most impact in decreasing SSB consumption as evidence indicates that soda and other SSB are more sensitive to price changes ${ }^{(46)}$. National experts have estimated that an excise tax of 1 cent per ounce for beverages containing added caloric sweetener would raise an estimated $\$$ US 14.9 billion of revenue in the first year of implementation and at a minimum would lead to a reduction of $10 \%$ in energy consumption $^{(15)}$.

\section{Strengths and limitations}

The present study's main strength is that the data are derived from a longitudinal, population-based survey of mothers. The main limitation is that the measurement of consumption of SSB was imprecise because it was based on mothers' report. Other limitations include: underestimation of SSB consumption, especially if the child is in child care; lack of information about quantity of SSB consumption; and lack of information about maternal dietary behaviours, which have been associated with child dietary behaviour ${ }^{(47,48)}$. In addition, we were not able to assess the children's BMI. Finally, the PRAMS-2 weighted response rate, $43.6 \%$, was low and there were significant differences between the PRAMS responders and PRAMS-2 responders that may bias the estimates of these analyses. Given that soda and other SSB consumption is higher among low-income and non-white youth ${ }^{(11,49)}$, these findings may have underestimated the consumption of SSB in the present sample given that PRAMS-2 nonresponders were more likely to be non-white, of lower income and lower education levels.

\section{Conclusions}

The identification of significant risk factors for soda and other SSB consumption by young children may act as an impetus for policy recommendations, future research and interventions targeting parents of young children. Although prevention of childhood obesity has emerged as a national priority and has received unprecedented emphasis by the White House ${ }^{(50)}$, there has been limited attention directed towards understanding the early-life risk factors for childhood obesity and successful interventions that target intergenerational predictors of excess weight of poor diet quality. Furthermore, recent state and federal legislations calling for increased taxes on soda and other $\operatorname{SSB}^{(16,51,52)}$ have omitted discussions and projections of the potential positive and health-promoting effect that these policies could have on the nutritional profile of low-income and minority mothers and young children ${ }^{(16)}$.

\section{Acknowledgements}

Sources of funding: B.R.G. was supported by the Graduate Student Internship Program from the Maternal and Child Health Resource Information Center funded by the US Department of Health and Human Services' Maternal and Child Health Bureau. Conflict of interest: The authors declare no conflict of interest. Authors' contributions: B.R.G. reviewed the literature, conducted the analyses 
and co-wrote the article. K.D.R. conceptualized the project, assisted in developing the analytic tables and co-wrote the article. D.S.M. assisted in interpreting the data and editing the manuscript. Acknowledgements: The authors acknowledge and thank all members of the Obesity Working Group at the Oregon Department of Human Services for their comments and contribution during the initial phases of this project. Specifically they would like to acknowledge and thank Helen Bellanca, Robin Stanton and Jennifer Young for their thoughtful comments, feedback and encouragement. Furthermore, the authors would like to acknowledge Alfredo Sandoval for his continued support and technical assistance with data management and execution. The authors would like to thank the Oregon PRAMS team for their hard work and commitment to state-wide data monitoring and surveillance. Finally, B.R.G. would like to acknowledge the Maternal and Child Health/Children Youth and Families Concentration at the Harvard School of Public Health for their support of this research and B.R.G.'s doctoral training.

\section{References}

1. Warren JJ, Weber-Gasparoni K, Marshall TA et al. (2009) A longitudinal study of dental caries risk among very young low SES children. Community Dent Oral Epidemiol 37, 116-122.

2. Vartanian LR, Schwartz MB \& Brownell KD (2007) Effects of soft drink consumption on nutrition and health: a systematic review and meta-analysis. Am J Public Health 97, 667-675.

3. Kranz S, Smiciklas-Wright H, Siega-Riz AM et al. (2005) Adverse effect of high added sugar consumption on dietary intake in American preschoolers. J Pediatr 146, 105-111.

4. Brownell KD \& Frieden TR (2009) Ounces of prevention the public policy case for taxes on sugared beverages. $N$ Engl J Med 360, 1805-1808.

5. Ogden CL, Carroll MD, Curtin LR et al. (2010) Prevalence of high body mass index in US children and adolescents, 2007-2008. JAMA 303, 242-249.

6. Singh AS, Mulder C, Twisk JWR et al. (2008) Tracking of childhood overweight into adulthood: a systematic review of the literature. Obes Rev 9, 474-488.

7. Harris G (2008) Development of taste and food preferences in children. Curr Opin Clin Nutr Metab Care 11, 315-319.

8. Dietz W (1994) Critical periods in childhood for the development of obesity. Am J Clin Nutr 59, 955-959.

9. Mei Z, Grummer-Strawn LM \& Scanlon KS (2003) Does overweight in infancy persist through the preschool years? An analysis of CDC Pediatric Nutrition Surveillance System data. Soz Praventivmed 48, 161-167.

10. Esposito L, Fisher JO, Mennella JA et al. (2009) Developmental perspectives on nutrition and obesity from gestation to adolescence. Prev Chronic Dis 6, A94.

11. Wang YC, Bleich SN \& Gortmaker SL (2008) Increasing caloric contribution from sugar-sweetened beverages and $100 \%$ fruit juices among US children and adolescents, 1988-2004. Pediatrics 121, e1604-e1614.

12. Mennella JA, Ziegler P, Briefel R et al. (2006) Feeding infants and toddlers study: the types of foods fed to hispanic infants and toddlers. J Am Diet Assoc 106, Suppl. 1, 96-106.

13. Petti S, Cairella G \& Tarsitanl G (2000) Rampant early childhood dental decay: an example from Italy. $J$ Public Health Dent 60, 159-166.
14. Warner ML, Harley K, Bradman A et al. (2006) Soda consumption and overweight status of 2-year-old MexicanAmerican children in California. Obesity (Silver Spring) 14, 1966-1974.

15. Brownell KD, Farley T, Willett WC et al. (2009) The public health and economic benefits of taxing sugar-sweetened beverages. $N$ Engl J Med 361, 1599-1605.

16. Sturm R, Powell LM, Chriqui JF et al. (2010) Soda taxes, soft drink consumption, and children's body mass index. Health Aff (Millwood) 29, 1052-1058.

17. Chriqui JF, Eidson SS, Bates H et al. (2008) State sales tax rates for soft drinks and snacks sold through grocery stores and vending machines, 2007. J Public Health Policy 29, 226-249.

18. Adams MM, Shulman HB, Bruce C et al. (1991) The Pregnancy Risk Assessment Monitoring System: design, questionnaire, data collection and response rates. Paediatr Perinat Epidemiol 5, 333-346.

19. Rosenberg KD, Gelow JM \& Sandoval AP (2003) Pregnancy intendedness and the use of periconceptional folic acid. Pediatrics 111, 1142-1145.

20. Oregon Department of Human Services, Health Services (2000) Oregon PRAMS First Year Report, 1998-99. Portland, OR: Office of Family Health; available at http:// public.health.oregon.gov/HEALTHYPEOPLEFAMILIES/DATA REPORTS/PRAMS/9899/Pages/index.aspx

21. Höfler M, Pfister H, Lieb R et al. (2005) The use of weights to account for non-response and drop-out. Soc Psychiatry Psychiatr Epidemiol 40, 291-299.

22. American Academy of Pediatrics (2001) The use and misuse of fruit juice in pediatrics. Pediatrics 107, 1210-1213.

23. Stephens MB, Keville MP, Hathaway NE et al. (2009) Clinical inquiries. When is it OK for children to start drinking fruit juice? J Fam Pract 58, E3.

24. Taveras EM, Gillman MW, Kleinman K et al. (2010) Racial/ ethnic differences in early-life risk factors for childhood obesity. Pediatrics 125, 686-695.

25. Centers for Disease Control and Prevention (updated 2011) About BMI for Adults. http://www.cdc.gov/healthyweight/ assessing/bmi/adult_bmi/index.html (accessed July 2008).

26. Ziegler P, Hanson C, Ponza M et al. (2006) Feeding Infants and Toddlers Study: meal and snack intakes of hispanic and non-hispanic infants and toddlers. J Am Diet Assoc 106, 1 Suppl. 1, 107-123.

27. Mennella JA \& Beauchamp GK (2002) Flavor experiences during formula feeding are related to preferences during childhood. Early Hum Dev 68, 71-82.

28. Lande B, Andersen LF, Veierød MB et al. (2004) Breastfeeding at 12 months of age and dietary habits among breast-fed and non-breast-fed infants. Public Health Nutr 7 , 495-503.

29. Harrington $S$ (2008) The role of sugar-sweetened beverage consumption in adolescent obesity: a review of the literature. J Sch Nurs 24, 3-12.

30. Lim S, Zoellner JM, Lee JM et al. (2009) Obesity and sugarsweetened beverages in African-American preschool children: a longitudinal study. Obesity (Silver Spring) 17, 1262-1268.

31. Malik VS, Schulze MB \& Hu FB (2006) Intake of sugarsweetened beverages and weight gain: a systematic review. Am J Clin Nutr 84, 274-288.

32. Duffey KJ \& Popkin BM (2006) Adults with healthier dietary patterns have healthier beverage patterns. J Nutr 136, 2901-2907.

33. Touger-Decker R \& van Loveren C (2003) Sugars and dental caries. Am J Clin Nutr 78, issue 4, 881S-892S.

34. Fiorito LM, Marini M, Mitchell DC et al. (2010) Girls' early sweetened carbonated beverage intake predicts different patterns of beverage and nutrient intake across childhood and adolescence. J Am Diet Assoc 110, 543-550.

35. Fiorito LM, Marini M, Francis LA et al. (2009) Beverage intake of girls at age $5 \mathrm{y}$ predicts adiposity and weight 
status in childhood and adolescence. Am J Clin Nutr 90 , 935-942.

36. Thompson FE, McNeel TS, Dowling EC et al. (2009) Interrelationships of added sugars intake, socioeconomic status, and race/ethnicity in adults in the United States: National Health Interview Survey, 2005. J Am Diet Assoc 109, 1376-1383

37. Rehm C, Matte T, Van Wye G et al. (2008) Demographic and behavioral factors associated with daily sugarsweetened soda consumption in New York City adults. J Urban Health 85, 375-385.

38. Drewnowski A (2009) Obesity, diets, and social inequalities. Nutr Rev 67, Suppl. 1, S36-S39.

39. Drewnowski A (2007) The real contribution of added sugars and fats to obesity. Epidemiol Rev 29, 160-171.

40. Drewnowski A \& Specter S (2004) Poverty and obesity: the role of energy density and energy costs. Am J Clin Nutr 79, 6-16.

41. Johnson SL, Clark L, Goree K et al. (2008) Healthcare providers' perceptions of the factors contributing to infant obesity in a low-income Mexican American Community. J Spec Pediatr Nurs 13, 180-190.

42. del Rio-Navarro BE, Velazquez-Monroy O, Sanchez-Castillo $\mathrm{CP}$ et al. (2004) The high prevalence of overweight and obesity in Mexican children. Obesity (Silver Spring) 12, 215-223.

43. Ward CL (2008) Parental perceptions of childhood overweight in the Mexican American population: an integrative review. J Sch Nurs 24, 407-416.
44. Ariza A, Chen E, Binns $\mathrm{H}$ et al. (2004) Risk factors for overweight in five- to six-year-old Hispanic-American children: a pilot study. J Urban Health 81, 150-161.

45. Position of the American Dietetic Association (2008) Nutrition guidance for healthy children ages 2 to 11 years. J Am Diet Assoc 108, 1038-1047.

46. Andreyeva T, Long MW \& Brownell KD (2010) The impact of food prices on consumption: a systematic review of research on the price elasticity of demand for food. $A m J$ Public Health 100, 216-222.

47. Gruber KJ \& Haldeman LA (2009) Using the family to combat childhood and adult obesity. Prev Chronic Dis 6, A106.

48. Francis LA, Ventura AK, Marini M et al. (2007) Parent overweight predicts daughters/' increase in BMI and disinhibited overeating from 5 to 13 years. Obesity (Silver Spring) 15, 1544-1553.

49. Hamasha AA-H, Warren JJ, Levy SM et al. (2006) Oral health behaviors of children in low and high socioeconomic status families. Pediatr Dent 28, 310-315.

50. Wojcicki JM \& Heyman MB (2010) Let's move - childhood obesity prevention from pregnancy and infancy onward. $N$ Engl J Med 362, 1457-1459.

51. Brownell KD, Farley T, Willett WC et al. (2009) The public health and economic benefits of taxing sugar-sweetened beverages. $N$ Engl J Med 361, 1599-1605.

52. Dellava JE, Bulik CM \& Popkin BM (2010) Price changes alone are not adequate to produce long-term dietary change. J Nutr 140, 1887-1891. 